Pain Physician. 2005;8:263-266, ISSN 1533-3159

\title{
InCIDENCE OF INTRAVASCULAR Uptake DURINg Fluoroscopically GUIDEd LUMBar Disc InJeCtions: A Prospective Observational Study
}

\author{
Bradly S. Goodman, MD, Craig E. Lincoln, MD, Kedar K. Deshpande, MD, Robert B. Poczatek, MD, \\ Philip H. Lander, MD, and Michael J. DeVivo, DrPH
}

Background: Although there are many in vivo studies evaluating lumbar disc injections, no studies have described the occurrence of intravascular uptake of contrast on discography. This phenomenon, however, has been well documented for other fluoroscopically-guided, contrast-enhanced spinal injections.

Objectives: To document the phenomenon and incidence of intravascular uptake during fluoroscopically-guided, contrast-enhanced lumbar disc injections.

Design: A prospective, observational, community-based study.

Methods: The incidence of fluoroscopically-confirmed intravascular uptake of contrast material was documented in $160 \mathrm{pa}$ - tients representing a subset of individuals presenting to a small private community hospital for evaluation and treatment of lower back pain. These patients underwent fluoroscopically-guided lumbar disc injections for therapeutic and/or diagnostic purposes.

Results: A total of 280 discs from L1-2 to $L 5-S 1$ were studied. The degree of disc degeneration of the evaluated discs was scored using the Adams' scoring criteria for intervertebral disc degeneration. The incidence of intravascular uptake as well as any correlation between stage of disc degeneration and intravascular uptake was statistically evaluated. A total of 40 out of 280 discs (14.3\%) demonstrated intravascular uptake. Detection of intravascular uptake usually required real-time fluoroscopy. There was no statistical correlation between the degree of disc degeneration and the incidence of intravascular uptake. No disc infections or other adverse sequelae occurred.

Conclusion: This is the first study, to our knowledge, that addresses the incidence of intravascular uptake during lumbar disc injections in patients with low back pain. The presence of intravascular uptake may have implications both clinically and diagnostically in regards to interpretation of lumbar discography and adverse events related to loss of injected medications into the vascular system.

Keywords: Lumbar disc injections, discography, intravascular uptake, fluoroscopy
Lumbar disc injections have been widely used both for diagnostic as well as therapeutic purposes (1-5). Although there are many studies evaluating lumbar discography and intradiscal steroid injections, none of the studies reported the existence of intravascular uptake (IVU) during the procedures.

Initial reports suggest that the disc

From: Department of Physical Medicine and Rehabilitation, University of Missouri at Columbia, and Alabama Orthopedic and Spine Center, Birmingham, AL; The Orthopedic Center, Huntsville, AL; Orthopedic and Spine Center at Polaris, Columbus, $\mathrm{OH}$; Neurosurgical Associates, Department of Radiology, University of Alabama at Birmingham, Birmingham, AL.

Address Correspondence:

Bradly S. Goodman, MD, Alabama Orthopedic and Spine Center, 52 Medical Park East Dr., Suite 115, Birmingham, AL 35235

E-mail: drspudhead@aol.com

Disclaimer: There was no external funding in prepa-

ration of this manuscript.

Conflict of Interest: None

Manuscript received on 5/17/2005

Revision submitted on 6/30/2005

Accepted for publication on 6/30/2005 is avascular throughout life (6-8), while others (9-11) believe that disc injury itself stimulates vascular ingrowth. Yet Kauppilla et al (12) have noted that "...vascular changes occurred before degeneration of the disc at every lumbar level, suggesting that disturbances in the nutritional supply may precede degeneration."

With the number of therapeutic interventions aimed at intervertebral discs increasing significantly over the past several years, the potential clinical significance of vascularity of the intervertebral disc becomes important to address. Although there are many studies evaluating lumbar discography and intradiscal steroid injections, we are not aware of any study in the literature that addresses the incidence of IVU of contrast material during the performance of these procedures.

IVU during contrast injection of zygapophysial joints, medial branches, and epidural spaces is reported (13-16). When IVU occurs, this may have implications on the diagnostic usefulness of the injection. Intravascular uptake may affect the operator's ability to appropriately pressurize the disc during discography, and hence, influence its interpretation. Additionally, the ability to therapeutically treat the disc itself with various biochemical mediators may be affected as well. Systemic side effects of intravascular uptake may also need to be considered. Although there may be many unexplained consequences of disc vascularity, our primary purpose was to document the phenomenon and incidence of intravascular uptake during lumbar disc injections.

\section{Methods}

Informed consent was obtained from all participants and patient confidentiality was maintained. All lumbar disc injections were performed at an outpatient surgery center using contrast enhancement and fluoroscopic guidance. Each patients was placed in the prone position and the skin was prepped in a sterile fashion. Intravenous access was obtained and prior to the procedure, the patients were premedicat- 


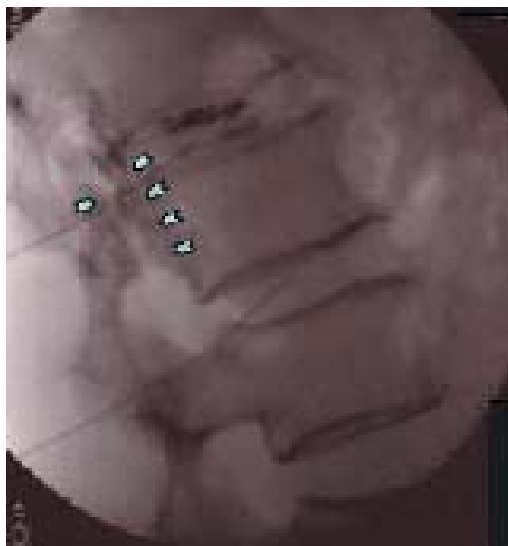

(A)Lateral fluoroscopic image demonstrating needles in the L1/2 and L2/3 discs. The L1/2 disc demonstrates contrast filling the disc with epidural leak (arrowheads) but no intravascular uptake. The L2/3 disc has not been injected.

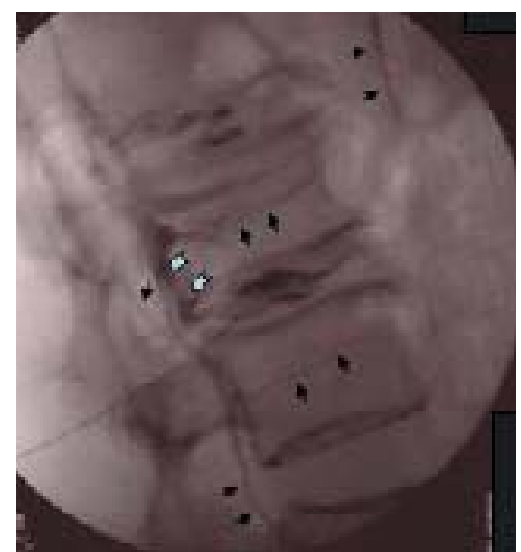

(B) Injection of contrast into the $\mathrm{L} 2 / 3$ disc demonstrates flow into the disc space as well as epidural leak (arrowheads) and intravascular uptake (arrows). This phenomenon is best seen under live fluoroscopy.
Fig.1. Intravascular uptake at L2/3 and epidural leak at L1/2, L2/3. ed with one gram of cefazolin.

Fluoroscopic guidance using oblique imaging was used to maximally visualize the appropriate disc levels. The skin and soft tissues was anesthetized with $1 \%$ lidocaine, followed by percutaneous placement of 22-gauge spinal needles into the discs under fluoroscopic oblique imaging. Needle placement was then confirmed on PA and lateral imaging to insure that the needles were placed into the center of the disc. Aspiration of the disc for possible blood was performed at this time. Approximately $1 \mathrm{~mL}$ of iohexol (Omnipaque $^{\circledR}$, Amersham Health, Princeton, $\mathrm{NJ}$ ) was instilled into the disc to ensure appropriate intradiscal spread. Once this was confirmed, $0.25 \mathrm{~mL}$ of preservative-free normal saline containing $25 \mathrm{mg}$ of cefazolin was instilled into the disc to reduce the potential risk of infection. No disc space infections occurred in this pro- spective study. Pressure monitoring was performed for most of the diagnostic injections, but was not correlated with the occurrence of intravascular uptake. Most intravascular injections were noted during live fluoroscopy.

With therapeutic intradiscal steroid injections, a combination of triamcinolone acetonide and $0.25 \%$ bupivacaine was injected into the discs under fluoroscopic visualization. The volume of injectate depended upon the amount the disc would accept and how many levels were being injected. No more than $3 \mathrm{~mL}$ of triamcinolone $(40 \mathrm{mg} / \mathrm{mL})$ was injected per patient. Between each syringe of injectate, approximately 2-3 mL of additional Omnipaque was instilled under real time fluoroscopy to further evaluate spread of the injectate. The spread of contrast enabled evaluation of the stage of disc degeneration and evidence of epidural leak, in addition to signs of IVU. Similarly, during provocative discography, approximately $3 \mathrm{~mL}$ of contrast was injected into each disc to evaluate elicited pain and contrast spread. Symptomatic discs were then injected with triamcinolone per the protocol noted above.

For the purposes of this study, data were collected regarding the levels of injection, needle aspiration and flash, disc morphology, epidural leak and incidence of IVU. A musculoskeletal radiologist reviewed all of the fluoroscopic images to confirm IVU and to grade the disc mor-

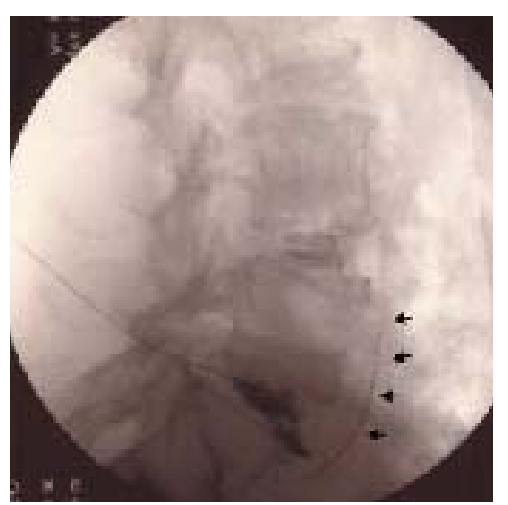

(C) Contrast injection into the L5/S1 disc demonstrating a moderately degenerative disc with intravascular uptake into the inferior vena cava (arrows). Note the intravascular uptake has dissipated at the L4/5 disc.

Fig. 2. Intravascular uptake at L4/5 and L5/SI 
phology utilizing a standardized scale, established by Adams et al (17).

Frequencies and percentages of IVU were calculated for each stage of degeneration both overall and within each vertebral level. Statistical significance of differences in IVU between stages of degeneration was assessed by a two-tailed chisquare test; $\mathrm{p}$ values $<0.05$ were considered to be statistically significant.

\section{RESULTS}

This study included 280 lumbar intervertebral disc levels performed on 160 patients. This represented 119 L5/S1, 119 L4/5, $31 \mathrm{~L} 3 / 4,10 \mathrm{~L} 2 / 3,1 \mathrm{~L} 1 / 2$ discs. A total of 40 out of 280 discs demonstrated IVU

(14.3\%). Examples of IVU are shown in figures 1 and 2 . Of these discs, $23 \mathrm{~L} 5 / \mathrm{S} 1$ (19.3\%), 15 L4/5 (12.6\%), 2 L3/4 (6.5\%), $0 \mathrm{~L} 2 / 3$, and $0 \mathrm{~L} 1 / 2$ were noted to have IVU. (Table 1) There was no statistical correlation between the degree of disc degeneration and the incidence on IVU (Table 2).

It was necessary to look for intravascular uptake during live fluoroscopy and observe for washout for several seconds. Intravascular injection could easily be overlooked, as contrast often appeared simultaneously in the disc. Spread of contrast was always seen within the disc when IVU occurred. It was useful to watch the vena cava for contrast flow during live fluoroscopy. Repositioning the needle did

Table 1. Intravenous uptake (IVU) in discs at various lumbar spinal levels and the incidence of epidural leakage of contrast and aspiration of blood

\begin{tabular}{|l|c|c|c|c|c|c|}
\hline & \# of discs & \# of IVU & \% IVU & $\begin{array}{c}\text { Epidural } \\
\text { Leak }\end{array}$ & $\begin{array}{c}\text { \% Epidural } \\
\text { leak }\end{array}$ & $\begin{array}{c}\text { Aspiration } \\
\text { of blood }\end{array}$ \\
\hline L5/S1 & 119 & 23 & 19.3 & 56 & 47.5 & 1 \\
\hline L4/5 & 119 & 15 & 12.6 & 59 & 50.0 & 0 \\
\hline L3/4 & 31 & 2 & 6.5 & 14 & 41.2 & 0 \\
\hline L2/3 & 10 & 0 & 0 & 4 & 40.0 & 0 \\
\hline L1/2 & 1 & 0 & 0 & 1 & 100.0 & 0 \\
\hline
\end{tabular}

Table 2. IVU as a function of disc degeneration. There was no relationship between degree of disc degeneration and IVU

\begin{tabular}{|l|c|c|c|c|}
\hline Location & Stage & No IVU & IVU & Total \\
\hline L5-S1 & 2 & 1 & $1(50 \%)$ & 2 \\
\hline & 3 & 12 & $0(0 \%)$ & 12 \\
\hline & 4 & 58 & $14(19.4 \%)$ & 72 \\
\hline & 5 & 25 & $8(24.2 \%)$ & 33 \\
\hline L4-L5 & Total & $\mathbf{9 6}$ & $\mathbf{2 3}(\mathbf{1 9 . 3} \%)$ & $\mathbf{1 1 9}$ \\
\hline & 2 & 5 & $0(0 \%)$ & 5 \\
\hline & 3 & 8 & $2(20 \%)$ & 10 \\
\hline & 4 & 55 & $9(14.1 \%)$ & 64 \\
\hline & 5 & 36 & $4(10 \%)$ & 40 \\
\hline & Total & $\mathbf{1 0 4}$ & $\mathbf{1 5 ( 1 2 . 6 \% )}$ & $\mathbf{1 1 9}$ \\
\hline & & & & 3 \\
\hline & 2 & 3 & $0(0 \%)$ & 6 \\
\hline & 3 & 6 & $0(0 \%)$ & 14 \\
\hline & 4 & 12 & $2(14.3 \%)$ & $\mathbf{3 1}$ \\
\hline & 5 & 8 & $0(0 \%)$ & $\mathbf{2 ( 6 . 5 \% )}$ \\
\hline
\end{tabular}

not consistently eliminate the IVU.

\section{Discussion}

In this prospective, observational study of 280 lumbar disc injections, the overall incidence of IVU was $14.3 \%$. There have been no previous studies documenting the occurrence of IVU during lumbar disc injections, but our data suggest that it occurs at a higher incidence than with caudal or lumbar transforaminal injections $(10.9 \%$ and $10.8 \%$ respectively) $(14,15)$. Only S1 and cervical transforaminal epidurals have a higher reported incidence $(21.3 \%$ and $19.4 \%$ respectively) $(13,14)$.

Use of observed blood in the needle hub ("flash") and aspiration (1 disc) was virtually never seen, and therefore was not predictive of IVU. Furman et al $(13,14)$ and Sullivan et al (15) postulated that in cervical transforaminal as well as other spinal injections, there is not enough pressure in the venous system to result in spontaneous blood flow into the needle hub. However, during contrast or medication injection, there is enough positive pressure to keep these smaller vessels distended, resulting in intravascular injection $(13,15)$. A similar phenomenon may exist during lumbar disc injections.

Contrast and other medications (steroids, bupivacaine, cefazolin) were injected in varying quantities despite the combination of IVU and intradiscal spread. None of the patients experienced symptoms or any adverse sequelae from IVU of the injectates.

The presence of IVU during lumbar spinal injections may have various implications. IVU may affect interpretation of provocation discography if intradiscal pressure is not raised sufficiently to elicit concordant pain, although epidural leak is a more common phenomenon. Efficacy of current or future therapeutic intradiscal injections may be adversely affected by loss of injectate into the vascular system. Injection of newer therapeutic agents also raises the concern for potential systemic complications with IVU. On the other hand, vascularization of lumbar discs may lead to potential systemic therapies directed at modifying biochemical mediators within the disc.

\section{ConcLusion}

This is the first study, to our knowledge, that addresses the incidence of intravascular uptake of contrast during 
lumbar discography in patients with low back pain. IVU occurred commonly during discography and was noted about $14 \%$ of the time. There was no statistical correlation between the degree of disc degeneration and the incidence of IVU. Intravascular injection could easily be overlooked, as contrast often spread simultaneously into the disc. The presence of IVU may have implications clinically and diagnostically regarding interpretation of lumbar discography and adverse events related to loss of injected medications into the vascular system.

\section{ACKNOWLEDGEMENT}

The expert assistance with manuscript preparation by Ms. Susan Gambill is gratefully acknowledged.

\section{RefERENCES}

1. Carragee EJ, Tanner CM, Khurana S, Hayward C, Walsh J, Date E, Troung T, Rossi $M$, Hagle $C$. The rates of false-positive lumbar discography in select patients without low back symptoms. Spine 2000; 25:13731381.

2. Derby $\mathrm{R}$, Lee $\mathrm{SH}$, Chen Y. A prospective analysis of lumbar discography findings in select participants without low back symptoms. North American Spine Society $18^{\text {th }}$ Annual Meeting Abstracts, Spine J 2003; 3:55.

3. Khot A, Bowditch M, Powell J, Sharp D. The use of intradiscal steroid therapy for lumbar spinal discogenic pain: a randomized controlled trial. Spine 2004; 29:833-837.

4. Simmons JW, McMillin JN, Emery SF, Kimmich SJ. Intradiscal steroids. A prospective double-blind clinical trial. Spine 1992; 17 (6 Suppl):S172-175

5. Walsh TR, Weinstein JN, Spratt KF, Lehmann TR, Aprill C, Sayre H. Lumbar discography in normal subjects: A controlled prospective study. J Bone Joint Surg Am 1990; 72:1081-1088.

6. Ferguson WR. Some observations on the circulation in fetal and infant spine. J Bone Joint Surg Am 1950; 32: 640-648

7. Ratcliffe JF. The arterial anatomy of the adult human lumbar vertebral body: a mi-

Author Affiliation:

Bradly S. Goodman, MD

Assistant Professor

Dept. of Physical Medicine and Rehab.

University of Missouri at Columbia

Alabama Orthopedic and Spine Center

52 Medical Park East Drive, Suite 115

Birmingham, AL 35235

E-mail: drspudhead@aol.com

\section{Craig E. Lincoln, MD}

Interventional Pain Physician

The Orthopedic Center

927 Franklin St.

Huntsville, AL 35801

E-mail: cclinc@aol.com

\section{Kedar K. Deshpande, MD}

Interventional Pain Physician

Orthopedic and Spine Center at Polaris

1120 Polaris Parkway,

Suite 202

Columbus, $\mathrm{OH} 43240$

E-mail: Kedardmd@hotmail.com
Robert B. Poczatek, MD

Physical Medicine and Rehabilitation

Neurosurgical Associates

833 St. Vincents Dr.

Birmingham, AL 35223

rpoczatek@neurosurgicalbirmingham.com

Philip H. Lander, MD

Associate Professor

Department of Radiology

University of Alabama at Birmingham

Jefferson Tower, Suite N 316

619 19th Street South

Birmingham, AL 35249-6830

E-mail: plander@uabmc.edu

\section{Michael J. DeVivo, Dr.P.H}

Professor

Dept. of Physical Medicine and Rehab.

University of Alabama at Birmingham

Spine Rehabilitation Center

1717 6th Ave. South

Birmingham, AL 35249

E-mail: DeVivo@uab.edu croarteriographic study. J Anat 1980; 131 (1):57-79.

8. Whalen JL, Parke WW, Mazur JM, Stauffer ES. The intrinsic vasculature of developing vertebral end plates and its nutritive significance to the intervertebral discs. J Pediatr Orthop 1985; 5 (4): 403-410.

9. Hirsch C, Schajowicz F. Studies on structural changes in the lumbar annulus fibrosus. Acta Orthop Scand 1953; 22:184-231.

10. Jackson HC II, Winkelmann RK, Bickle WH. Nerve endings in the human lumbar spinal column and related structures. J Bone Joint Surg Am 1966; 48:1272-1281.

11. Yasuma T, Makino E, Saito S, Inui M. Clinicopathological study on lumbar intervertebral disc herniation. 3. Comparison between surgical materials and clinical data. Orthop Trauma 1986; 29:1817-1826.

12. Kauppila LI. Ingrowth of Blood Vessels in Disc Degeneration. J Bone Joint Surg 1995;77:26-31.
13. Furman MB, Giovanniello MT, O’Brien EM. Incidence of intravascular penetration in transforaminal cervical epidural steroid injections. Spine 2003; 28:21-25.

14. Furman M, O’Brien E, Zgleszewski T. Incidence of intravascular penetration in transforaminal lumbosacral epidural injections. Spine 2000; 25:2628-2632.

15. Sullivan WJ, Willick SE, Chira-Adisai W, Zuhosky J, Tyburski M, Dreyfuss P, Prather $\mathrm{H}$, Press JM. Incidence of Intravascular Uptake in lumbar spinal injection procedures. Spine 2000; 25:481-486.

16. Kaplan M, Dreyfuss P, Halbrook B, Bogduk N. The ability of lumbar medial branch blocks to anesthesize the zygapophyseal joint. A physiologic challenge. Spine 1988; 23 (17): 1847-1852.

17. Adams MA. Dolan P. Hutton WC. The stag es of disc degeneration as revealed by discogram. J Bone Joint Surg Br 1986; 68(1): 36-41. 